\title{
Reducing demand for antibiotic prescriptions: evidence from an online survey of the general public on the interaction between preferences, beliefs and information, United Kingdom, 2015
}

Laurence S J Roope ${ }^{1,2}$, Sarah Tonkin-Crine ${ }^{2,3}$, Christopher C Butler ${ }^{2,3}$, Derrick Crook ${ }^{2,4,5,6}$, Tim Peto ${ }^{2,4,5,6}$, Michele Peters7, A Sarah Walker $2,4,5$, Sarah Wordsworth $1,2,4$

1. Health Economics Research Centre, Nuffield Department of Population Health, University of Oxford, Oxford, United Kingdom

2. The National Institute for Health Research Health Protection Research Unit in Healthcare Associated Infections and

Antimicrobial Resistance at the University of Oxford, Oxford, United Kingdom

3. Nuffield Department of Primary Care Health Sciences, University of Oxford, Oxford, United Kingdom

4. National Institute for Health Research Oxford Biomedical Research Centre, John Radcliffe Hospital, University of Oxford, Oxford, United Kingdom

5. Nuffield Department of Clinical Medicine, University of Oxford, John Radcliffe Hospital, University of Oxford, Oxford, United Kingdom

6. Oxford University Hospitals National Health Service Trust, Oxford, United Kingdom

7. Health Services Research Unit, Nuffield Department of Population Health, University of Oxford, Oxford, United Kingdom

Correspondence: Laurence Roope (laurence.roope@dph.ox.ac.uk)

Citation style for this article:

Roope Laurence S J, Tonkin-Crine Sarah, Butler Christopher C, Crook Derrick, Peto Tim, Peters Michele, Walker A Sarah, Wordsworth Sarah, Reducing demand for antibiotic prescriptions: evidence from an online survey of the general public on the interaction between preferences, beliefs and information, United Kingdom, 2015. Euro Surveill. 2018;23(25):pii=1700424. https://doi.org/10.2807/1560-7917. ES.2018.23.25.1700424

Article submitted on 30 Jun 2017 / accepted on 19 Apr 2018 / published on 21 Jun 2018

Background: Antimicrobial resistance (AMR), a major public health threat, is strongly associated with human antibiotic consumption. Influenza-like illnesses (ILI) account for substantial inappropriate antibiotic use; patient understanding and expectations probably play an important role. Aim: This study aimed to investigate what drives patient expectations of antibiotics for ILI and particularly whether AMR awareness, risk preferences (attitudes to taking risks with health) or time preferences (the extent to which people prioritise good health today over good health in the future) play a role. Methods: In 2015, a representative online panel survey of 2,064 adults in the United Kingdom was asked about antibiotic use and effectiveness for ILI. Explanatory variables in multivariable regression included AMR awareness, risk and time preferences and covariates. Results: The tendency not to prioritise immediate gain over later reward was independently strongly associated with greater awareness that antibiotics are inappropriate for ILI. Independently, believing antibiotics were effective for ILI and low AMR awareness significantly predicted reported antibiotic use. However, 272 (39\%) of those with low AMR awareness said that the AMR information we provided would lead them to ask a doctor for antibiotics more often, significantly more than would do so less often, and in contrast to those with high AMR awareness ( $p$ <.0001). Conclusion: Information campaigns to reduce $A M R$ may risk a paradoxical consequence of actually increasing public demand for antibiotics.
Public antibiotic stewardship campaigns should be tested on a small scale before wider adoption.

\section{Introduction}

Antimicrobial resistance (AMR) is a growing threat to global health and the economy. A recent report commissioned by the United Kingdom (UK) government estimated that AMR could reduce global gross domestic product by $2-3.5 \%$, costing up to USD $10^{14}$ (EUR $\left.1.39 \times 10^{14}\right)$ from 2014 to 2050 [1]. Many pathogens are becoming resistant faster than alternative antibiotics are being developed [2]. There are strong associations between the volume of human antibiotic consumption and AMR [3]. Reducing AMR requires better antibiotic stewardship $[4,5]$.

Respiratory tract infections (RTIs) account for most human antibiotic use $[6,7]$. However, RTIs are often viral, and more than half of the antibiotics taken for influenza-like-illnesses (ILI) are unnecessary. Even in healthcare systems such as the UK's National Health Service, where general practitioners (GPs) act as gatekeepers to prescriptions, patient expectations probably play an important role in unnecessary antibiotic consumption $[8,9]$. Several multi-faceted public campaigns in high-income countries have successfully reduced antibiotic use, but isolating the impact of campaign elements intended to improve AMR awareness is difficult [10]. 


\section{Box}

Information about antimicrobial resistance given to questionnaire respondents, United Kingdom, 2015

"Antibiotic resistance occurs when an antibiotic loses its ability to effectively control or kill growing bacteria. It is an increasingly serious threat to public health. Without effective antibiotics, many routine treatments will become increasingly dangerous. Setting broken bones, and even basic operations, rely on access to antibiotics that work. Antibiotic resistance is believed to be caused by unnecessary use of antibiotics, and inappropriate use, such as not taking them as prescribed, skipping doses, or saving them for later use."

A large proportion of the public in the UK believe antibiotics are effective for ILI [11]. However, little is known about the links between AMR awareness and expectations of antibiotics, or of the influence of risk preferences (attitudes to taking risks with health) or time preferences (the extent to which people prioritise good health today over good health in the future). These latter characteristics predict other health-related behaviours [12-14]; we hypothesised that they might be associated with inappropriate antibiotic use. Moreover, the probable impact of public information campaigns about AMR on antibiotic demand is uncertain. Therefore, we surveyed a representative sample of the general adult population in the UK to assess AMR awareness, the role that this and other factors (particularly risk and time preferences) play in unnecessary antibiotic consumption for ILI, and the impact of information provision (awareness campaigns) on future unnecessary antibiotic use. The study's key outcomes were individuals' beliefs about effectiveness and reported use of antibiotics for ILI.

\section{Methods}

\section{Survey design}

We developed a web-based survey to ask the general public questions about antibiotics and AMR. Survey development was informed by discussions with three clinical experts (a GP and two junior doctors) and a patient and public involvement group $(n=7)$.

The survey (Supplement 1) asked respondents to consider Health State A: "You have a fever, aching muscles, a headache, a dry chesty cough, a sore throat, and tiredness." This description was intended to convey ILI, for which antibiotics are often expected but not generally necessary or useful. Health State A was described symptomatically, rather than specifying a 'flu' or 'virus', for two reasons: Firstly, individuals may interpret such terms differently. Secondly, people may know that antibiotics are inappropriate for viral conditions, yet not recognise Health State A symptoms as more consistent with a viral than a bacterial infection.

Respondents were asked how they would respond in the hypothetical situation of having experienced
Health State A for 5 days - in particular whether they would go to a doctor and request antibiotics. They were also asked whether they thought antibiotics would be likely to help this condition, and about their antibiotic use in the previous 12 months for similar conditions. Participants with dependent children then answered analogous questions about the hypothetical situation of their youngest child being ill.

The survey captured information on a wide range of factors that might be associated with patient expectations for, and use of, antibiotics, including sociodemographic factors such as age, sex, ethnicity and health. A short-form questionnaire [15] captured personality traits - 'extraversion', ‘agreeableness', 'conscientiousness', 'neuroticism' and 'openness.' The survey also elicited respondents' attitudes to taking risks with health (risk preferences), and their prioritisation of good health today over good health in the future (time preferences).

The respondents were then given information (Box) that paraphrased text on the websites of four institutions aiming to improve awareness of AMR [16-19]. Participants were asked how surprising they found the information, and how it would influence (i) their future attendance at a doctor's surgery for conditions like Health State A; (ii) their likelihood of asking a doctor for antibiotics in future. Participants with children were asked analogous questions regarding how they would act for their youngest child.

\section{Risk and time preferences}

Risk preferences are typically elicited in surveys via a series of questions involving the choice between a lottery and a monetary outcome, e.g. "Which would you prefer to receive today: EUR 50, or a $50 \%$ chance of receiving nothing and a 50\% chance of receiving EUR 100." However, recent evidence suggests that risk (and time) preferences are domain-specific $[20,21]$. We therefore framed our elicitation method in a health context.

Alongside Health State A respondents were asked to consider Health State B: "You have a fever, chest pain, night sweats, a cough that brings up phlegm, loss of appetite, extreme tiredness, and some weight loss." Health State B was intended to represent a substantially more serious condition than $A$, such as tuberculosis or lung cancer. Respondents were asked to assign each health state a value from o (worst imaginable health state) to 10 . For the method to work, we needed respondents to recognise that Health State B was worse than A. However, it was important that it did not sound so severe that few respondents would ever take a gamble in which Health State B was a possible outcome. Following an internal pilot $(n=152$ participants), the words '....and some weight loss' were added to the original Health State B description to encourage more respondents to evaluate Health State $B$ as more severe than A. 
TABLE 1

Respondent characteristics, behavioural survey on antibiotic prescriptions, United Kingdom, $2015(\mathrm{n}=2,064)$

\begin{tabular}{|c|c|c|c|c|c|c|c|}
\hline \multirow[t]{2}{*}{ Variable } & \multicolumn{3}{|c|}{ Full sample } & \multicolumn{3}{|c|}{$\begin{array}{l}\text { Restricted sample with risk and time } \\
\text { preferences }\end{array}$} & \multirow[t]{2}{*}{$p$ value $^{a}$} \\
\hline & $\mathrm{N}$ with data & Mean & SD & $\mathrm{N}$ with data & Mean & SD & \\
\hline Age & 2,064 & 44 & 15.7 & 1,117 & 44.0 & 15.9 & 0.55 \\
\hline Household equivalent income (EUR) & 1,886 & 31,066 & 25,487 & 1,027 & 31,672 & 25,373 & 0.26 \\
\hline \multirow[t]{2}{*}{ Own self-rated health $(0-10)$} & 2,064 & 7.3 & 2.0 & 1,117 & 7.5 & 1.8 & 0.0001 \\
\hline & $\mathrm{N}$ with data & $\mathrm{n}$ & $\%$ & $\mathrm{~N}$ with data & $\mathrm{n}$ & $\%$ & \\
\hline Male & 2,061 & 994 & 48.2 & 1,117 & 500 & 44.8 & 0.0006 \\
\hline White & 2,042 & 1,821 & 89.2 & 1,107 & 1,000 & 90.3 & 0.07 \\
\hline Christian & 2,007 & 1,010 & 50.8 & 1,097 & 527 & 48.0 & 0.007 \\
\hline Higher-education & 2,047 & 954 & 46.6 & 1,112 & 552 & 49.6 & 0.003 \\
\hline Unemployed & 2,064 & 105 & 5.1 & 1,117 & 56 & 5.0 & 0.87 \\
\hline Sick/disabled & 2,064 & 82 & 4.0 & 1,117 & 40 & 3.6 & 0.32 \\
\hline Married/civil partnership/live with partner & 2,064 & 1,351 & 65.5 & 1,117 & 697 & 62.4 & 0.002 \\
\hline United Kingdom-born & 2,064 & 1,856 & 89.9 & 1,117 & 1,006 & 90.1 & 0.82 \\
\hline \multicolumn{8}{|l|}{ Geographic region } \\
\hline East Anglia & 2,064 & 171 & 8.3 & 1,117 & 107 & 9.6 & 0.02 \\
\hline East Midlands & 2,064 & 129 & 6.3 & 1,117 & 77 & 6.9 & 0.19 \\
\hline West Midlands & 2,064 & 181 & 8.8 & 1,117 & 95 & 8.5 & 0.65 \\
\hline London & 2,064 & 297 & 14.4 & 1,117 & 160 & $14 \cdot 3$ & 0.93 \\
\hline North East & 2,064 & 80 & 3.9 & 1,117 & 36 & 3.2 & 0.10 \\
\hline North West & 2,064 & 239 & 11.6 & 1,117 & 132 & 11.8 & 0.71 \\
\hline South East & 2,064 & 337 & 16.3 & 1,117 & 191 & 17.1 & 0.30 \\
\hline South West & 2,064 & 180 & 8.7 & 1,117 & 92 & 8.2 & 0.40 \\
\hline Yorkshire and Humberside & 2,064 & 166 & 8.0 & 1,117 & 76 & 6.8 & 0.02 \\
\hline Wales & 2,064 & 91 & 4.4 & 1,117 & 49 & 4.4 & 0.96 \\
\hline Scotland & 2,064 & 161 & 7.8 & 1,117 & 87 & 7.8 & 0.98 \\
\hline Northern Ireland & 2,064 & 32 & 1.6 & 1,117 & 15 & 1.3 & 0.41 \\
\hline \multicolumn{8}{|l|}{ Personality and behaviour ${ }^{b}$} \\
\hline & $\mathrm{N}$ with data & Mean & SD & $\mathrm{N}$ with data & Mean & SD & \\
\hline Extraversion & 2,064 & 5.9 & 1.9 & 1,117 & 5.8 & 2.0 & 0.001 \\
\hline Agreeableness & 2,064 & 7.0 & 1.6 & 1,117 & 6.9 & 1.6 & 0.20 \\
\hline Conscientiousness & 2,064 & 7.7 & 1.7 & 1,117 & 7.7 & 1.7 & 0.94 \\
\hline Neuroticism & 2,064 & 5.8 & 2.1 & 1,117 & 5.9 & 2.2 & 0.03 \\
\hline Openness & 2,064 & 6.8 & 1.6 & 1,117 & 6.9 & 1.7 & 0.04 \\
\hline \multirow[t]{2}{*}{ Risk-averse $^{c}$} & NR & NR & NR & 1,117 & 2.389 & 2.386 & NR \\
\hline & $\mathrm{N}$ with data & $\mathrm{n}$ & $\%$ & $\mathrm{~N}$ with data & $\mathrm{n}$ & $\%$ & \\
\hline Very low discounter & NR & NR & NR & 1,117 & 337 & 30.2 & NR \\
\hline
\end{tabular}

NR: not reported; SD: standard deviation.

a $\mathrm{p}$ values from t-tests for continuous and chi-squared test for categorical factors compare those with and without risk and time preference indicators.

${ }^{\mathrm{b}}$ Extraversion, agreeableness, conscientiousness, neuroticism, and openness were measured on a scale from 2 to 10.

c The risk-averse variable was measured on a scale from -9 to 9 .

Attitudes towards risk were elicited via a set of standard gamble questions with two options. The options varied in terms of the fictitious health state lasting 2 weeks that would be assigned to the respondent. In each question, Option 1 was described as being like a lottery: a respondent might be in Full Health, but could instead be in Health State B. In Option 2, the respondent would be guaranteed Health State A. Throughout the questions, the probability of Health State B in
Option 1 was varied, to elicit the probability required for a respondent to be indifferent between choosing Option 1's gamble and Option 2's guaranteed health state. Together with the subjective health state evaluations, this enabled construction of a risk aversion variable.

Time preferences were elicited via a similar series of questions, each containing two options. In Option 1, 
How survey respondents said information about AMR would affect the number of times that they and their children visit a doctor and request antibiotics for conditions like Health State A, United Kingdom, 2015 ( $\mathrm{n}=2,064)$

\begin{tabular}{|c|c|c|c|c|c|c|c|c|}
\hline & \multicolumn{4}{|c|}{ For oneself (adult) } & \multicolumn{4}{|c|}{ For one's child } \\
\hline & \multicolumn{2}{|c|}{$\begin{array}{l}\text { Find information on AMR } \\
\text { surprising }(n=705)\end{array}$} & \multicolumn{2}{|c|}{$\begin{array}{l}\text { Don't find information on } \\
\text { AMR surprising }(n=1,359)\end{array}$} & \multicolumn{2}{|c|}{$\begin{array}{l}\text { Find information on } \\
\text { AMR surprising }(n=370)\end{array}$} & \multicolumn{2}{|c|}{$\begin{array}{l}\text { Don't find information on } \\
\text { AMR surprising }(n=446)\end{array}$} \\
\hline & $\mathrm{n}$ & $\%$ & $\mathrm{n}$ & $\%$ & $n$ & $\%$ & $\mathrm{n}$ & $\%$ \\
\hline \multicolumn{9}{|l|}{ Visits to GP } \\
\hline Definitely visit less & 29 & 4.1 & 131 & 9.6 & 10 & 2.7 & 16 & 3.6 \\
\hline Probably visit less & 63 & 8.9 & 142 & 10.5 & 31 & 8.4 & 48 & 10.8 \\
\hline No change & 309 & 43.8 & 999 & 73.5 & 158 & 42.7 & 340 & 76.2 \\
\hline Probably visit more & 194 & 27.5 & 29 & 2.1 & 100 & 27.0 & 16 & 3.6 \\
\hline Definitely visit more & 89 & 12.6 & 16 & 1.2 & 63 & 17.0 & 7 & 1.6 \\
\hline Don't know & 21 & 3.0 & 42 & 3.1 & 8 & 2.2 & 19 & 4.3 \\
\hline $\mathrm{p}$ (change within group) ${ }^{\mathrm{a}}$ & \multicolumn{2}{|c|}{$<0.0001$} & \multicolumn{2}{|c|}{$<0.0001$} & \multicolumn{2}{|c|}{$<0.0001$} & \multicolumn{2}{|c|}{$<0.0001$} \\
\hline $\begin{array}{l}\text { p (difference between } \\
\text { groups) }\end{array}$ & \multicolumn{4}{|c|}{$<0.0001$} & \multicolumn{4}{|c|}{$<0.0001$} \\
\hline \multicolumn{9}{|l|}{ Ask for antibiotics } \\
\hline Definitely ask less & 40 & 5.7 & 194 & 14.3 & 18 & 4.9 & 31 & 7.0 \\
\hline Probably ask less & 72 & 10.2 & 182 & 13.4 & 48 & 13.0 & 63 & 14.1 \\
\hline No change & 303 & 43.0 & 897 & 66.0 & 132 & 35.7 & 312 & 70.0 \\
\hline Probably ask more & 179 & 25.4 & 23 & 1.7 & 105 & 28.4 & 13 & 2.9 \\
\hline Definitely ask more & 93 & 13.2 & 8 & 0.6 & 54 & 14.6 & 6 & 1.4 \\
\hline Don't know & 18 & 2.6 & 55 & 4.1 & 13 & 3.5 & 21 & 4.7 \\
\hline $\mathrm{p}$ (change within group) ${ }^{\mathrm{a}}$ & \multicolumn{2}{|c|}{$<0.0001$} & \multicolumn{2}{|c|}{$<0.0001$} & \multicolumn{2}{|c|}{$<0.0001$} & \multicolumn{2}{|c|}{$<0.0001$} \\
\hline $\begin{array}{l}\text { p (difference between } \\
\text { groups) }\end{array}$ & \multicolumn{4}{|c|}{$<0.0001$} & \multicolumn{4}{|c|}{$<0.0001$} \\
\hline
\end{tabular}

AMR: antimicrobial resistance; GP: general practitioner; ILI: influenza-like-illness

${ }^{a}$ Wilcoxon single-sample signed-rank test that the median value within each group is no change.

${ }^{\mathrm{b}}$ Wilcoxon rank-sum test comparing the distribution of responses in those who do and do not find the AMR information surprising. $\mathrm{p}$ values calculated excluding 'Don't know' category and coding a 5-point Likert scale for each variable.

respondents would immediately face 2 weeks of Health State A, followed by Full Health for the next 18 years. In Option 2, respondents would instead face 2 weeks of Health State $B$, at some specified time in the next 18 years, and Full Health at all other times. Throughout the questions, the timing of Health State B in Option 2 was varied, to elicit how far into the future it should occur for a respondent to be indifferent between Health State A now, and Health State B then. This enabled construction of variables indicating the extent to which respondents discount the future, including those who were never happy to accept Health State B, no matter how far into the future, but preferred Health State $A$ today. The latter individuals are referred to hereafter as 'very low discounters'. This indicates an extreme time preference where the personal discount rate is close to zero.

\section{Survey participants}

The survey was conducted online using a panel of respondents provided by Survey Sampling International (SSI), a data collection and market research company. SSI was commissioned to obtain a sample of at least 2,000 completed responses, representative of adult members of the general public in terms of sex, age, ethnicity and geographic region. The sample size was powered to quantify the proportion of individuals who believe antibiotics are effective for ILI, at a 95\% confidence level, with $2.5 \%$ precision and assuming $25 \%$ missing responses. Survey invitations were emailed to 6,280 SSI panel members resident in the UK.

A small incentive, worth approximately EUR 0.83, was offered for survey completion in the form of 'Nectar points' (a UK loyalty card scheme via which customers accrue discounts redeemable at various outlets). The invitations were sent over 3 weeks in May and June 2015. The first 152 responses were collected in an internal pilot, to confirm that there were no unexpected technical problems. As noted above, following the internal pilot, an amendment was made to the description of Health State B.

The SSI survey was undertaken outside the NHS setting and therefore did not need NHS ethical approval. Completion of the questionnaire was considered as indicating consent. Respondents were able to refuse to participate in the questionnaire at any stage in the 
TABLE 3

Differences in characteristics of those who would and would not 'definitely/probably' ask a doctor for antibiotics more often after receiving information about AMR, United Kingdom, $2015(\mathrm{n}=1,991)$

\begin{tabular}{|c|c|c|c|c|c|c|c|c|}
\hline & \multicolumn{3}{|c|}{$\begin{array}{l}\text { Would 'definitely/probably' ask } \\
\text { doctor for antibiotics more often }\end{array}$} & \multicolumn{3}{|c|}{$\begin{array}{l}\text { 'No change' or would 'definitely/ } \\
\text { probably' ask doctor for antibiotics } \\
\text { less often }\end{array}$} & Univariable ${ }^{a}$ & Multivariable $^{\mathrm{b}}$ \\
\hline \multicolumn{9}{|l|}{ Sociodemographic data } \\
\hline & $\mathrm{N}$ with data & $\mathrm{n}$ & $\%$ & $\mathrm{~N}$ with data & $\mathrm{n}$ & $\%$ & $p$ value & $p$ value \\
\hline Male & 302 & 174 & 57.6 & 1,687 & 781 & 46.3 & 0.0003 & 0.04 \\
\hline White & 300 & 233 & 77.7 & 1,674 & 1532 & 91.5 & $<0.0001$ & 0.60 \\
\hline Christian & 293 & 143 & 48.8 & 1,645 & 848 & 51.6 & 0.39 & 0.50 \\
\hline Higher education & 301 & 156 & 51.8 & 1,676 & 769 & 45.9 & 0.06 & 0.74 \\
\hline Unemployed & 303 & 13 & $4 \cdot 3$ & 1,688 & 84 & 5.0 & 0.61 & 0.74 \\
\hline Sick/disabled & 303 & 11 & 3.6 & 1,688 & 69 & 4.1 & 0.71 & 0.11 \\
\hline Married/partnered & 303 & 221 & 72.9 & 1,688 & 1089 & 64.5 & 0.004 & 0.03 \\
\hline \multirow[t]{2}{*}{ United Kingdom-born } & 303 & 262 & 86.5 & 1,688 & 1,535 & 90.9 & 0.02 & 0.96 \\
\hline & $\mathrm{N}$ with data & Mean & SD & $\mathrm{N}$ with data & Mean & SD & $p$ value & $p$ value \\
\hline Age (years) & 303 & 35 & 11.6 & 1,688 & 46 & 15.8 & $<0.0001$ & 0.47 \\
\hline Household income & 287 & $\begin{array}{c}\text { EUR } \\
30,793\end{array}$ & $\begin{array}{c}\text { EUR } \\
26,049\end{array}$ & 1,539 & $\begin{array}{c}\text { EUR } \\
31,226\end{array}$ & $\begin{array}{c}\text { EUR } \\
25,492\end{array}$ & 0.80 & 0.30 \\
\hline Own self-rated health $(0-10)$ & 303 & 7.0 & 2.0 & 1,688 & 7.4 & 2.0 & 0.0009 & 0.08 \\
\hline \multicolumn{9}{|l|}{ Personality } \\
\hline Extraversion & 303 & 6.0 & 1.4 & 1,688 & 5.9 & 2.0 & 0.23 & 0.26 \\
\hline Agreeableness & 303 & 6.9 & 1.5 & 1,688 & 7.0 & 1.6 & 0.53 & 0.82 \\
\hline Conscientiousness & 303 & 7.1 & 1.7 & 1,688 & 7.8 & 1.7 & $<0.0001$ & 0.27 \\
\hline Neuroticism & 303 & 5.8 & 1.7 & 1,688 & 5.8 & 2.2 & 0.92 & 0.85 \\
\hline Openness & 303 & 6.4 & 1.4 & 1,688 & 6.9 & 1.7 & $<0.0001$ & 0.002 \\
\hline \multicolumn{9}{|l|}{ Risk and time preferences } \\
\hline \multirow[t]{2}{*}{ Risk aversion } & 130 & 1.6 & 2.5 & 1,027 & 2.5 & 2.4 & 0.0003 & 0.11 \\
\hline & $\mathrm{N}$ with data & $\mathrm{n}$ & $\%$ & $\mathrm{~N}$ with data & $\mathrm{n}$ & $\%$ & $p$ value & $p$ value \\
\hline Very low discounter & 139 & 7 & 5.0 & 1,038 & 342 & 32.9 & $<0.0001$ & $<0.0001$ \\
\hline \multicolumn{9}{|l|}{ Attitudes to antibiotics and ILI } \\
\hline $\begin{array}{l}\text { Surprised by AMR } \\
\text { information }\end{array}$ & 303 & 272 & 89.8 & 1,688 & 415 & 24.6 & $<0.0001$ & $<0.0001$ \\
\hline $\begin{array}{l}\text { Believe antibiotics would } \\
\text { help Health State A }\end{array}$ & 303 & 232 & 76.6 & 1,688 & 514 & 30.5 & $<0.0001$ & $<0.0001$ \\
\hline \multirow[t]{2}{*}{$\begin{array}{l}\text { Taken antibiotics for Health } \\
\text { State A in last } 12 \text { months }\end{array}$} & 303 & 169 & 55.8 & 1,688 & 245 & $14 \cdot 5$ & $<0.0001$ & ND \\
\hline & $\mathrm{N}$ with data & Mean & SD & $\mathrm{N}$ with data & Mean & SD & $\mathrm{p}$ value & $p$ value \\
\hline Health State A rating & 303 & 6.3 & 2.3 & 1,688 & 5.5 & 2.1 & $<0.0001$ & ND \\
\hline
\end{tabular}

AMR: antimicrobial resistance; ILI: influenza-like illness; ND: not done; SD: standard deviation.

a t-test for continuous and chi-squared test for categorical factors.

${ }^{b}$ From a multivariable probit model including all factors. Model coefficients and further details are available in Supplement 2, Table 2.5, final column.

process. All data were processed in accordance with the UK Data Protection Act 1998.

\section{Statistical analysis}

Four dependent variables were initially modelled using probit regressions, each with several sets of independent variables; 'Believe antibiotics would help Health State A', 'Find AMR information surprising', 'Would ask doctor for antibiotics if I went', and 'Have taken antibiotics for a condition similar to Health State $\mathrm{A}$ in last 12 months'. The same models were then fitted to the dependent variables 'definitely/probably visit a doctor more often' and 'definitely/probably ask a doctor for antibiotics more often' in response to the provided AMR information. There was a 'prefer not to answer' option for questions on income, sex, ethnicity, religion and education, leading to slightly lower sample sizes for models including these independent variables. All models used complete cases (i.e. no missing variables) for specific groups of independent variables. Model 1 included sociodemographic data. Model 2 additionally adjusted for discounting and risk aversion. Model 3 also adjusted for personality. Model 4 also adjusted for awareness of AMR and that antibiotics are unlikely 


\section{FIGURE}

Probit regression models for the survey responses 'visiting doctor more' and 'asking for more antibiotics' in response to AMR information, United Kingdom, $2015(\mathrm{n}=1,769)$

A.

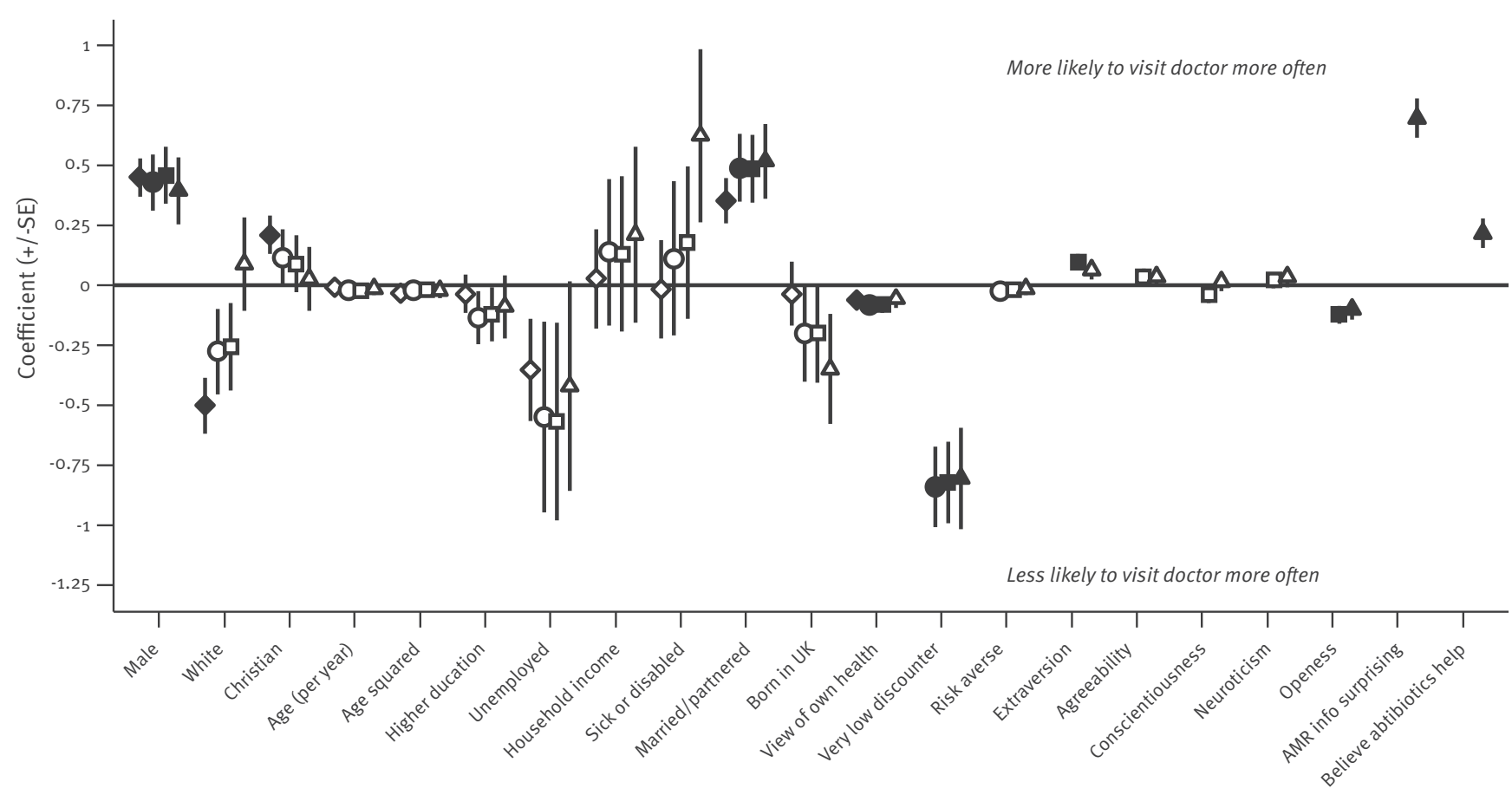

B.

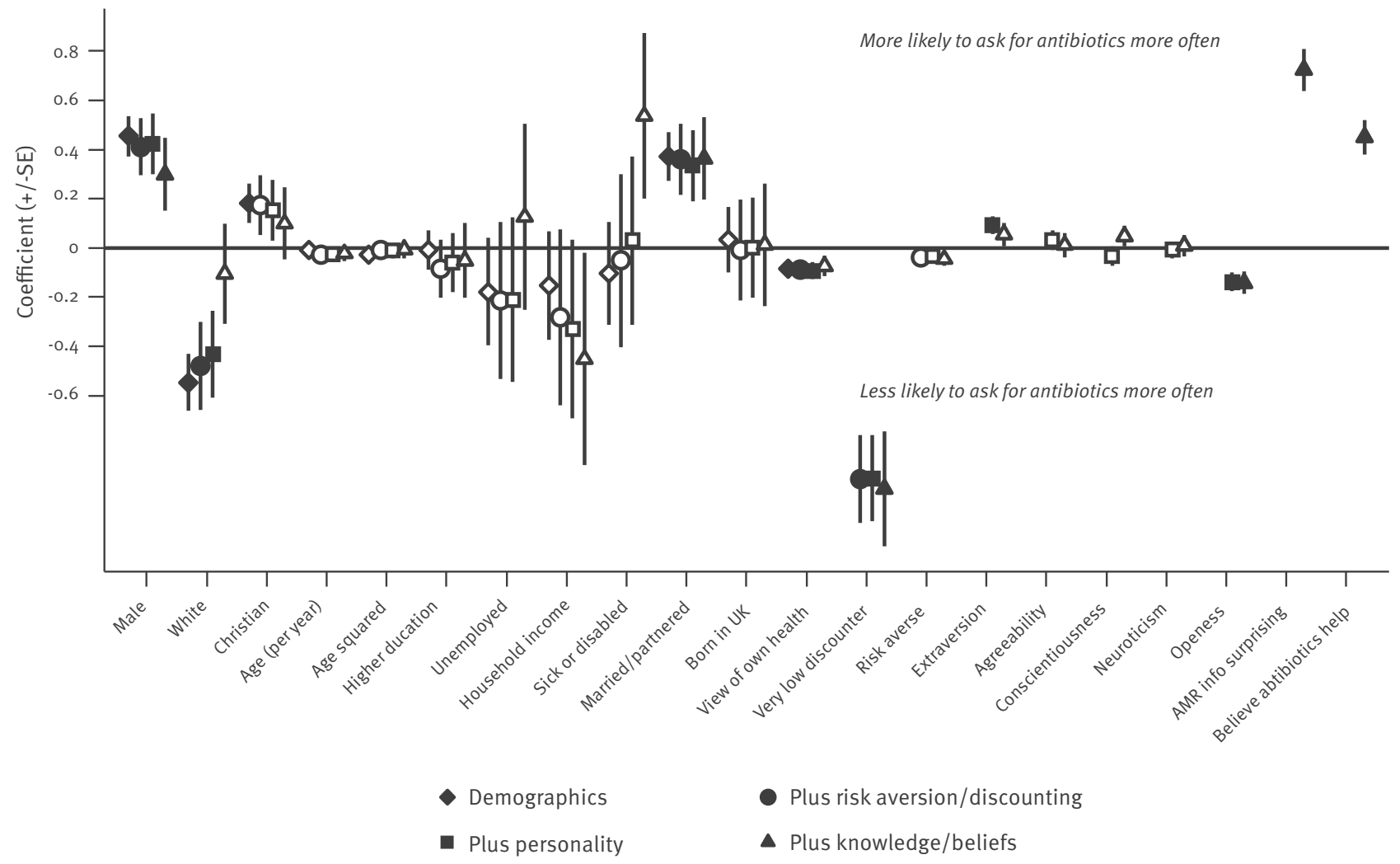

AMR: antimicrobial resistance; SE: standard error; UK: United Kingdom.

Solid symbols: $p<0.05$; empty symbols: $p>0.05$. See Supplement 2, Table 2.5 for full model details. 
TABLE 4

Percentage of different profiled groups 'definitely/probably' asking a doctor for antibiotics more often after receiving information about AMR, United Kingdom, $2015(\mathrm{n}=1,816)$

\begin{tabular}{|l|c|c|c|c|c|c|}
\hline \multirow{2}{*}{ Response to AMR information } & \multicolumn{5}{|c|}{ Cluster groups } \\
\cline { 2 - 6 } & Group 1 & Group 2 & Group 3 & Group 4 & Group 5 \\
\hline Total in cluster group & 1,055 & 77 & 73 & 347 & 264 & 1,816 \\
\hline 'Definitely/probably ask less often' or 'no change' & 853 & 63 & 64 & 320 & 187 & 1,487 \\
\hline 'Definitely/probably ask more often' & 176 & 8 & 9 & 17 & 66 & 276 \\
\hline 'Don't know' & 26 & 6 & 0 & 10 & 11 & 53 \\
\hline Percentage who would 'definitely/probably ask more often' & $16.7 \%$ & $10.4 \%$ & $12.3 \%$ & $4.9 \%$ & $25.0 \%$ & $15.2 \%$ \\
\hline Mean age (years) & 39.6 & 37.1 & 47.8 & 64.0 & 36.6 & 44.0 \\
\hline Percentage male & $48.4 \%$ & $55.8 \%$ & $43.8 \%$ & $60.8 \%$ & $34.9 \%$ & $48.2 \%$ \\
\hline Percentage white & $99.1 \%$ & $96.1 \%$ & $97.3 \%$ & $99.4 \%$ & $33.3 \%$ & $89.2 \%$ \\
\hline Percentage United Kingdom-born & $99.5 \%$ & $96.1 \%$ & $100.0 \%$ & $100.0 \%$ & $38.3 \%$ & $89.9 \%$ \\
\hline Percentage with higher education & $48.4 \%$ & $29.9 \%$ & $21.9 \%$ & $32.3 \%$ & $72.4 \%$ & $46.6 \%$ \\
\hline Percentage sick/disabled & $0 \%$ & $0 \%$ & $100 \%$ & $0 \%$ & $0 \%$ & $4.0 \%$ \\
\hline Mean household income (EUR) & 33.947 & 12,872 & 15,891 & 29,478 & 31,804 & 31,066 \\
\hline
\end{tabular}

AMR: antimicrobial resistance.

The Table shows the subset of characteristics which varied most across the different groups (key differences in italics). All characteristics are listed in Supplement 3, Table 3.1

to benefit ILI. Coefficients for sociodemographic and respondent characteristics in Models 2, 3 and 4 therefore correspond to residual effects not mediated through their impact on discounting, risk aversion, personality or awareness of AMR and the ineffectiveness of antibiotics for ILI. The 152 pilot participants were excluded from all models including risk aversion and time preferences. The relative quality of Models 1-4 was assessed by both the Akaike information criterion (AIC) and Bayesian information criterion (BIC). These standard tests assign values to each model and deem the model with the minimum value to have the highest quality. Subgroups of respondents sharing similar characteristics were identified using hierarchical clustering of the sociodemographic, health and personality variables. Income is reported in this paper in EUR, using the conversion rate from GBP applicable on 31 May 2015.

\section{Results}

\section{Respondent characteristics}

2,064 (33\%) of the 6,280 individuals contacted completed the survey. An additional 223 people began the questionnaire but did not complete it. A further 102 individuals clicked on the link in the invitation email but did not begin the questionnaire.

Table 1 provides some key characteristics of the respondents, including personality traits and risk and time preference indicators. The latter variables could only be estimated in 1,214 and 1,192 respondents, respectively, who evaluated Health State $B$ as worse than A. Elicitation of time preference variables additionally required respondents to assign Health State $A$ a score under 10 (Full Health). Those with and without risk/time indicators were broadly similar in terms of age, income, ethnicity, employment, country of origin and region of residence. However, fewer respondents with preference indicators were male $(p=0.0006)$, Christian $(p=0.007)$ or married/partnered $(p=0.002)$, and more had a higher education $(p=0.003)$. Those with preference indicators had lower 'extraversion,' $(p=0.001)$ and more 'neuroticism' $(p=0.03)$ and 'openness' $(p=0.04)$.

\section{Beliefs about antibiotic use}

A total of 988 (48\%) respondents said they would 'definitely/probably' visit the GP if they experienced Health State A for 5 days. In this situation, 706 of $1,816(39 \%)$ respondents would ask a GP for antibiotics. (The denominator here is less than 2,064 because 248 respondents said they would 'definitely not' visit the GP if they experienced Health State A for 5 days. In the survey (Supplement 1), these respondents were not asked the subsequent question "If you went to see a GP about this condition, do you think you would request antibiotics?") Some 762 (37\%) believed that antibiotics would 'definitely/probably' help and 426 (21\%) respondents reported taking antibiotics for ILI in the last 12 months. Some 430 (53\%) respondents believed that antibiotics would help their child if they had ILI, while $200(25 \%)$ said that their child had taken antibiotics for ILI during the last 12 months. A total of 705 (34\%) respondents were 'very/somewhat' surprised by the provided AMR information.

Models of 'Believe antibiotics would help Health State A', 'Find AMR information surprising', 'Would ask doctor for antibiotics if I went' and 'Have taken antibiotics for 
a condition similar to Health State A in last 12 months' indicated associations with several sociodemographic characteristics (Supplement 2, Tables 2.1-2.4). Being more extraverted was significantly positively associated with these outcomes, while being more conscientious, more open and a very low discounter were negatively associated. Adjusting for these traits, effect size and significance of many demographic characteristics declined or disappeared, and generally declined further after also adjusting for AMR awareness and for knowledge that antibiotics are unlikely to help ILI.

\section{Reported response to AMR information}

Of the 705 who found the AMR information 'very/ somewhat' surprising, $283(40 \%)$ said it would lead them to 'definitely/probably' visit a doctor more often, while 272 (39\%) said it would lead them to 'definitely/ probably' ask for antibiotics more often. These proportions were significantly higher than the respective percentages for 'definitely/probably' visiting a doctor, and asking for antibiotics less often (92 (13\%) and 112 (16\%), respectively; Wilcoxon single-sample sign-rank $\mathrm{p}<0.0001$ ) (Table 2). This distribution of responses differed significantly from those who did not find information on AMR surprising (both Wilcoxon rank-sum $p<0.0001)$. This adverse reaction to the information, among those surprised by it, was even stronger in the context of taking one's child to the doctor and requesting antibiotics for them.

Of the 1,359 who reported finding the AMR-information 'not very/not at all' surprising, 273 (20\%) said it would lead them to 'definitely/probably' visit a doctor less often, while $376(28 \%)$ said it would lead them to 'definitely/probably' ask for antibiotics less often, significantly higher than the respective percentages for 'definitely/probably' visiting a doctor, and asking for antibiotics, more often (Wilcoxon single-sample signrank $p<0.0001$ ). The majority of those who found the AMR information 'not very/not at all' surprising said it would lead to 'no change' in how often they would visit a doctor ( $\mathrm{n}=999 ; 74 \%$ ) or ask for antibiotics ( $\mathrm{n}=897$; $66 \%)$.

Several factors were univariably associated with 'definitely/probably' asking for antibiotics more often (Table 3).

In all specifications of the multivariable models (Figure), those who would 'definitely/probably' visit and 'definitely/probably' ask a doctor for antibiotics more often were significantly more likely to be male and married/partnered. They were independently significantly more likely to believe antibiotics are likely to help ILI, and more likely to be surprised by our AMR information, but less likely to be a very low discounter, and less open. Of the models including risk and time preferences, Model 4, which also adjusted for personality, AMR awareness and knowledge that antibiotics are unlikely to help ILI, was preferred to Models 2 and
3 according to both the AIC and BIC model selection tests.

\section{Cluster analysis}

Cluster Group 1 contained most (176/276; 64\%) respondents who would 'definitely/probably' ask for antibiotics more often, while Group 5 contained most of the remainder $(66 / 276 ; 24 \%$ ) (Table 4$)$. Group 5 contained the highest percentage of people who would 'definitely/probably' ask for antibiotics more often $(66 / 264 ; 25 \%)$, and Group 1 the second highest $(176 / 1,055 ; 17 \%)$. Group 1 and Group 5 had more income and were younger than the survey sample averages. Group 1 was $99 \%(1,046 / 1,055)$ white, almost $100 \%(1,050 / 1,055)$ UK-born and 48\% (511/1,055) male, while $48 \%(511 / 1,055)$ had a higher-education. Group 5 was $33 \%$ white $(88 / 264), 38 \%(101 / 264)$ UK-born and $35 \%(92 / 264)$ male and $72 \%(191 / 264)$ with a higher education.

\section{Discussion}

In this study, lack of AMR-awareness and the belief that antibiotics would help ILI were strongly associated with self-reported likelihood of consulting and requesting antibiotics for ILI, and with antibiotic consumption. This lack of knowledge was a mediating variable in the association between consulting/requesting antibiotics for ILI and sociodemographic characteristics. This may indicate a role for public information campaigns, perhaps targeted at specific population groups. It is encouraging that respondents who were unsurprised by the AMR information provided said it would make them less likely to consult a GP or request antibiotics. It is therefore possible that over a longer timeframe, repeated exposure to $A M R$ information could reduce antibiotic requests. However, many with poor AMR awareness said they would react to such information by consulting doctors and asking for antibiotics more, not less often. This identifies a potential paradox where the overall impact of a public campaign could be increased demand for antibiotics. Such phenomena have been found in public health campaigns outside the field of AMR $[22,23]$. A meta-analysis of fear-appeal health campaigns found that fear-appeal messages, while often effective, are likely to backfire if people do not believe they are able to adequately protect themselves from the threat, a possibility which seems plausible here [24].

Being a very low discounter was strongly associated with awareness of AMR and the likely minimal benefit from antibiotics for ILI, and with not consulting a doctor or requesting antibiotics for ILI. Like personality, it was a mediating variable in the association between consulting/requesting antibiotics for ILI and sociodemographic characteristics. Attaching substantial importance to health in the very distant future may encourage both the acquisition of health literacy, and avoiding choices that could damage long-term health prospects for minor short-term benefits. We found no evidence of a significant association of risk-aversion 
with attitudes towards antibiotic use or resistance. It cannot safely be concluded, however, that risk preferences do not play a role in the demand for antibiotics. The lack of significance could stem from risk aversion leading some people to take antibiotics, e.g. to avoid uncertainty over complications, but others to avoid antibiotics, for fear of possible AMR-related problems.

\section{Strengths and limitations}

An important limitation is that respondents' reported future behaviour in response to the AMR information may differ from what they would actually do in real life. The reported paradoxical behaviour, where some respondents said they would ask for antibiotics more, not less often in response to the AMR information, may not reflect their actual behaviour.

Another limitation is that only members of the online survey panel participated. Thus the sample was limited to those with internet-access, basic computer literacy and an interest in completing surveys. However, use of this panel also meant that age, sex, ethnicity, geographic region and proportion unemployed were broadly representative of the general population in the UK, although the percentage with higher education (47\%) was higher than the population average (27\%) and mean income was lower.

A major strength was our inclusion of variables not generally used in epidemiological studies, relating to personality and, particularly, risk and time preferences. Knowledge of how these characteristics are associated with AMR awareness and appropriate antibiotic use could help inform public campaigns. For example, advertising budgets could be used more efficiently by concentrating advertisements in specific media (television channels/programmes, websites and social media) that are typically consumed by audiences with these characteristics. Unfortunately, the risk and time variables could only be estimated in, respectively, $58 \%$ and $59 \%$ of the sample.

\section{Comparison with existing literature}

There have been several surveys of public perceptions of AMR and appropriate use of antibiotics in primary care and a systematic review of the public's knowledge and beliefs about AMR $[11,25]$. However, none of these studies have explicitly evaluated responses to information about AMR or considered a role for risk or time preferences. Our descriptive results broadly concur with previous studies in confirming wide-ranging misunderstanding regarding antibiotic efficacy for ILI and lack of knowledge about AMR.

Several public campaigns in high-income countries have successfully reduced antibiotic use in primary care $[10,26]$. In France, following a multi-faceted 'antibiotics are not automatic' campaign, there was a substantial decrease in antibiotic prescriptions between 2002 and 2007 compared with the pre-intervention period 2000 to 2002 [27]. A review by Huttner et al. concluded that because nearly all successful campaigns were multi-faceted, it was difficult to unpick whether improvements were due to changes in the behaviour of patients, physicians or both, or whether the observed improvements were related to confounding factors which would have happened in the absence of the campaigns [10]. All campaigns reviewed tried to convey the seriousness of AMR, sometimes using a fear message; most campaigns also tried to educate the public that antibiotics are ineffective for respiratory infections. Some campaigns encouraged people to complete antibiotic courses, an area of controversy [28]. A 1999 campaign in the UK to educate the public about appropriate antibiotic use and to raise AMR awareness was associated with improved knowledge about antibiotics but there was no evidence of reduced antibiotic use [29]. Campaigns in Greece and Spain also failed to show such an effect [10].

\section{Conclusion}

Although based on hypothetical reported future behaviour, the results of this study suggest that public information campaigns to reduce unnecessary antibiotic use may risk a paradoxical consequence of increased, rather than decreased, public demand for antibiotics. This does not negate the potentially important role such campaigns may have; several public information campaigns have proven effective as part of multi-faceted interventions to reduce unnecessary prescribing. However, it underscores the importance of testing public antibiotic stewardship information campaigns on a small scale before rolling them out widely. Choosing the right words may be critical to success, and different strategies may be needed for different population subgroups [30].

Most effective campaigns have tried to convey that $A M R$ is a serious problem, while also explaining that antibiotics are ineffective for respiratory infections [10]. The information tested in this study contained only the former element. Information containing both elements might have performed better. One of the strongest predictors of self-reported inappropriate antibiotic use, and of negative response to the AMR information, was belief in the efficacy of antibiotics for ILI. Information explicitly challenging this belief, perhaps coupled with reassurance that cold and influenza symptoms are easily treated with rest, fluids and paracetamol, could potentially form the basis for a successful public campaign. More research is urgently needed on finding an effective way to communicate this important message.

\section{Acknowledgements}

Firstly we wish to thank all the people who completed our survey. We also thank Joanna Coast, Richard Smith, Helen Barker, Jane Simms, Ali Vaughan, Charles Crichton, Timothy Walker, Amy Mason, Claire Scarborough, Nicola Fawcett, Teresa Street, Oluwafemi Akinremi, Apostolos Tsiachristas, James Buchanan, Jilles Fermont, Rachael Morton, Elizabeth Stokes, Filipa Landeiro, Jacqueline Murphy, Barbara Kitchener, Yaling Yang, Richéal Burns, Peter Eibich, Ines 
Rombach, Anees Pari, Thomas Rouyard, Oliver Rivero-Arias, Christopher Rooney, Amar Marthi, Sam Williams, and various members of our Public and Patient Involvement (PPI) group for a wide variety of useful comments and suggestions on preliminary versions of our survey instrument.

This work was supported by the National Institute for Health Research Health Protection Research Unit (NIHR HPRU) in Healthcare Associated Infections and Antimicrobial Resistance at the University of Oxford and in partnership with Public Health England (PHE) [grant number HPRU2012-10041]. Michele Peters is a Senior Research Scientist supported by the Department of Health funded Policy Research Unit on Quality and Outcomes of Person Centred Care (QORU), a collaboration between the London School of Economics and Political Science (LSE) and the Universities of Kent and Oxford. Tim Peto and Derrick Crook are National Institute for Health Research (NIHR) Senior Investigators. The funders had no involvement in the study design, collection, analysis or interpretation of data, or in writing the article and deciding to submit it for publication.

\section{Conflict of interest}

None declared.

\section{Authors' contributions}

LR led the design of the questionnaire, with significant contributions from ST-C, TP, MP, ASW, and SW. LR led the data analysis, with contributions from ST-C, MP, CCB, ASW, and SW. All authors helped to interpret the results of the study. LR led the drafting of the paper, with contributions from all authors. All authors have seen and approved the final article.

\section{References}

1. The Review on Antimicrobial Resistance. Antimicrobial resistance: tackling a crisis for the health and wealth of nations. London: UK Government; 2014. Available from: https://amr-review.org/sites/default/files/AMR\%20Review\%20 Paper\% $20-\% 20$ Tackling $\% 20 a \% 20$ crisis $\% 2$ for $\% 20$ the $\% 20$ health $\% 20$ and $\% 20$ wealth $\% 200 \%$ 20nations_1.pdf

2. Leeb M. Antibiotics: a shot in the arm. Nature. 2004;431(7011):892-3. https://doi.org/10.1038/431892a PMID: 15496888

3. Goossens H, Ferech M, Vander Stichele R, Elseviers MESAC Project Group. Outpatient antibiotic use in Europe and association with resistance: a cross-national database study. Lancet. 2005;365(9459):579-87. https://doi.org/10.1016/ S0140-6736(05)70799-6 PMID: 15708101

4. Bartlett JG. A call to arms: the imperative for antimicrobial stewardship. Clin Infect Dis. 2011;53(Suppl 1):S4-7. https://doi. org/10.1093/cid/cir362 PMID: 21795727

5. Laxminarayan R. Antibiotic effectiveness: balancing conservation against innovation. Science. 2014;345(6202):1299-301. https://doi.org/10.1126/ science.1254163 PMID: 25214620

6. Low D. Reducing antibiotic use in influenza: challenges and rewards. Clin Microbiol Infect. 2008;14(4):298-306. https:// doi.org/10.1111/j.1469-0691.2007.01910.x PMID: 18093237

7. Petersen I, Johnson AM, Islam A, Duckworth G, Livermore DM, Hayward AC. Protective effect of antibiotics against serious complications of common respiratory tract infections: retrospective cohort study with the UK General Practice Research Database. BMJ. 2007;335(7627):982. https://doi. org/10.1136/bmj.39345.405243.BE PMID: 17947744

8. Cockburn J, Pit S. Prescribing behaviour in clinical practice: patients' expectations and doctors' perceptions of patients' expectations--a questionnaire study. BMJ. 1997;315(7107):5203. https://doi.org/10.1136/bmj.315.7107.520 PMID: 9329308

9. Coenen S, Michiels B, Renard D, Denekens J, Van Royen P. Antibiotic prescribing for acute cough: the effect of perceived patient demand. Br J Gen Pract. 2006;56(524):183-90. PMID: 16536958
10. Huttner B, Goossens H, Verheij T, Harbarth SCHAMP consortium. Characteristics and outcomes of public campaigns aimed at improving the use of antibiotics in outpatients in high-income countries. Lancet Infect Dis. 2010;10(1):1731. https://doi.org/10.1016/S1473-3099(09)70305-6 PMID: 20129146

11. McNulty CAM, Nichols T, French DP, Joshi P, Butler CC. Expectations for consultations and antibiotics for respiratory tract infection in primary care: the RTI clinical iceberg. $\mathrm{Br}$ J Gen Pract. 2013;63(612):e429-36. https://doi.org/10.3399/ bjgp13X669149 PMID: 23834879

12. Kang MI, Ikeda S. Time discounting and smoking behavior: evidence from a panel survey $\left({ }^{\star}\right)$. Health Econ. 2014;23(12):1443-64. https://doi.org/10.1002/hec.2998 PMID: 24136867

13. Picone G, Sloan F, Taylor D Jr. Effects of risk and time preference and expected longevity on demand for medical tests. J Risk Uncertain. 2004;28(1):39-53. https://doi. org/10.1023/B:RISK.0000009435.11390.23

14. Anderson LR, Mellor JM. Predicting health behaviors with an experimental measure of risk preference. J Health Econ. 2008;27(5):1260-74. https://doi.org/10.1016/j. jhealeco.2008.05.011 PMID: 18621427

15. Rammstedt $B$, John OP. Measuring personality in one minute or less: A 10-item short version of the Big Five Inventory in English and German. J Res Pers. 2007;41(1):203-12. https:// doi.org/10.1016/j.jrp.2006.02.001

16. What is Antibiotic Resistance and Why is it a problem? Boston: Alliance for the Prudent Use of Antibiotics (APUA). [Accessed Nov 2015]. Available from: http://www.tufts.edu/med/apua/ about_issue/antibiotic_res.shtml

17. World Health Organization (WHO). Antimicrobial resistance. Geneva; WHO; 2018. Available from: http://www.who.int/ mediacentre/factsheets/fs194/en/

18. Become an antibiotic guardian. London: Public Health England; [Accessed Nov 2015]. Available from: www.antibioticguardian. com

19. The Antibiotic Awareness Campaign. London: NHS; 2015 , http://www.nhs.uk/NHSEngland/ARC/Pages/AboutARC.aspx

20. Dohmen T, Falk A, Huffman D, Sunde U, Schupp J, Wagner GG. Individual risk attitudes: Measurement, determinants, and behavioral consequences. J Eur Econ Assoc. 2011;9(3):522-50. https://doi.org/10.1111/j.1542-4774.2011.01015.x

21. Jimura K, Myerson J, Hilgard J, Keighley J, Braver TS, Green L. Domain independence and stability in young and older adults' discounting of delayed rewards. Behav Processes. 2011;87(3):253-9. https://doi.org/10.1016/j. beproc.2011.04.006 PMID: 21550384

22. Nyhan B, Reifler J, Richey S, Freed GL. Effective messages in vaccine promotion: a randomized trial. Pediatrics. 2014;133(4):e835-42. https://doi.org/10.1542/peds.2013-2365 PMID: 24590751

23. Cho H, Salmon CT. Unintended effects of health communication campaigns. J Commun. 2007;57(2):293-317. https://doi. org/10.1111/j.1460-2466.2007.00344.x

24. Peters GJ, Ruiter RA, Kok G. Threatening communication: a critical re-analysis and a revised meta-analytic test of fear appeal theory. Health Psychol Rev. 2013;7(sup1) Suppl 1;S8 31. https://doi.org/10.1080/17437199.2012.703527 PMID: 23772231

25. McCullough AR, Parekh S, Rathbone J, Del Mar CB, Hoffmann TC. A systematic review of the public's knowledge and beliefs about antibiotic resistance. J Antimicrob Chemother. 2016;71(1):27-33. https://doi.org/10.1093/jac/dkv310 PMID: 26459555

26. Goossens H, Guillemot D, Ferech M, Schlemmer B, Costers M, van Breda M, et al. National campaigns to improve antibiotic use. Eur J Clin Pharmacol. 2006;62(5):373-9. https://doi. org/10.1007/s00228-005-0094-7 PMID: 16568344

27. Sabuncu E, David J, Bernède-Bauduin C, Pépin S, Leroy $M$ Boëlle PY, et al. Significant reduction of antibiotic use in the community after a nationwide campaign in France, 2002-2007. PLoS Med. 2009;6(6):e1000084. https://doi.org/10.1371/ journal.pmed.1000084 PMID: 19492093

28. Llewelyn MJ, Fitzpatrick JM, Darwin E, SarahTonkin-Crine, Gorton C, Paul J, et al. The antibiotic course has had its day. BMJ. 2017;358:j3418. https://doi.org/10.1136/bmj.j3418 PMID: 28747365

29. McNulty CA, Boyle P, Nichols T, Clappison P, Davey P. Don't wear me out--the public's knowledge of and attitudes to antibiotic use. J Antimicrob Chemother. 2007;59(4):727-38. https://doi.org/10.1093/jac/dkl558 PMID: 17307770

30. Smith RA, MacGeorge EL, Hackman NM, M'ikanatha NM. Campaign preparation for complex initiatives: a person-centred approach to audience segmentation of parents' antibiotic 
stewardship. Health Commun. 2017;1-10.; Epub ahead of print. https://doi.org/10.1080/10410236.2017.1384345

\section{License and copyright}

This is an open-access article distributed under the terms of the Creative Commons Attribution (CC BY 4.0) Licence. You may share and adapt the material, but must give appropriate credit to the source, provide a link to the licence, and indicate if changes were made.

This article is copyright of the authors, 2018. 